\title{
IN SITU FORMING OXIDISED HYALURONIC ACID/ADIPIC ACID DIHYDRAZIDE HYDROGEL FOR PREVENTION OF EPIDURAL FIBROSIS AFTER LAMINECTOMY
}

\author{
M.H. Hu ${ }^{1,2}$, K.C. Yang ${ }^{3}$, Y.H. Sun ${ }^{2}$, Y.C. Chen ${ }^{4}$, S.H. Yang ${ }^{2, *}$ and F.H. Lin ${ }^{1,5}$ \\ ${ }^{1}$ Institute of Biomedical Engineering, College of Medicine and College of Engineering, \\ National Taiwan University, No. 1, Sec. 4, Roosevelt Road, Taipei 106, Taiwan \\ ${ }^{2}$ Department of Orthopaedics, National Taiwan University College of Medicine and National Taiwan \\ University Hospital, No.1, Sec. 1, JenAi Road, Taipei 100, Taiwan \\ ${ }^{3}$ School of Dental Technology, College of Oral Medicine, Taipei Medical University, \\ 250 Wuxing Street, Taipei 110, Taiwan \\ ${ }^{4}$ Department of Orthopaedics, Far Eastern Memorial Hospital, No.21, Sec. 2, Nanya S. Road, \\ Banciao District, New Taipei City 220, Taiwan \\ ${ }^{5}$ Institute of Biomed Engineering and Nanomedicine, National Health Research Institutes, \\ 35 Keyan Road, Zhunan, Miaoli County 350, Taiwan
}

\begin{abstract}
Post-operative epidural fibrosis is a biological response after laminectomy that may lead to clinical symptoms, such as radicular pain. An ideal material for prevention of epidural fibrosis should be able to inhibit fibroblast adhesions and reduce formation of scar tissue. An injectable hydrogel would be the material of choice for this purpose, since it could fill an irregular surgical defect completely, gelate in situ and be delivered in a minimally-invasive manner. The objective of this study was to evaluate, in vitro and in vivo, the cytocompatibility and anti-adhesive effect of an oxidised hyaluronic acid/adipic acid dihydrazide (oxiHA/ADH) hydrogel. Different cell types present in the spine were used to test the cytocompatibility of the hydrogel. The hydrogel extraction medium had no deleterious effects on neural cells (PC-12), but reduced fibroblasts viability (NIH/3T3). Although the hydrogel did not change the release of lactate dehydrogenase from myoblasts (C2C12) and Schwann cells (RSC96), the extraction medium concentration slightly affected the mitochondrial activity of these two cell types. qPCR showed that the hydrogel down-regulated S100a and $P 4 h b$ expression in NIH/3T3 cells, supporting the hypothesis that the hydrogel might inhibit fibroblast activity. The animal study showed a reduction of scar tissue formation as well as severity of adhesion between scar tissue and the dura mater in a rat laminectomy model. Superficially, the peel-off test showed significantly decreased tenacity. In conclusion, the oxi-HA/ADH hydrogel is a promising injectable and thermosensitive material for prevention of post-operative epidural fibrosis.
\end{abstract}

Keywords: Injectable hydrogel, thermosensitive, hyaluronic acid, epidural fibrosis, laminectomy.

*Address for correspondence: Dr Shu-Hua Yang, Department of Orthopaedics, National Taiwan University College of Medicine and National Taiwan University Hospital, No.1, Sec. 1, JenAi Road, Taipei 100, Taiwan. Telephone: +886 23123456 Fax: +886 23224112 E-mail: shuhuayang@ntu.edu.tw

\section{Introduction}

Laminectomy is used to explore the spinal canal and decompress the neural elements during spinal surgery. Post-operative epidural fibrosis is a normal biological response after laminectomy, which leads to post-laminectomy dura mater adhesion (Semra et al., 2015). Fibrosis is the replacement of epidural fat with fibrotic tissue, which binds the dura mater and the nerve roots to the anterior and posterior structures (de Tribolet et al., 1998; Robertson, 1996). In addition, it can cause symptomatic problems, such as radicular pain. Ross et al. (1996) show a close relationship between epidural adhesions and recurrent radicular pain or lower back pain after a successful lumbar discectomy. In addition, epidural adhesion leads to difficulties during a revision surgery. The rate of complications, such as iatrogenic nerve root injury or dura mater tear, remains unpredictably high in revision surgeries (Burton, 1991). Therefore, prevention of epidural fibrosis and adhesion is an imperative for a successful laminectomy.

The growth of fibrous connective tissue into the surgical haematoma of the paraspinal muscle results in fibrosis after laminectomy (Yong-Hing et al., 1980; Jacobs et al., 1980). To avoid haematoma infiltration, anti-adhesive materials are proposed to act as an occupying spacer preventing blood from entering 
the epidural space after laminectomy (Jacobs et al., 1980). A variety of biological, pharmacological and synthetic materials have been tested in vitro or used in vivo as space-occupying agents. Free or pedicle fat graft (Barberá et al., 1978), Silastic (Alkalay et al., 2003), methylene blue (Farrokhi et al., 2011), ADCON-L (Einhaus et al., 1997), Vicryl mesh (Nussbaum et al., 1990), methacrylate (Lawson et al., 1991), carboxymethyl cellulose (Rodgers et al., 2003), polyethylene oxide (Rodgers et al., 2003), haemostatic agents (Doğulu et al., 2009; Songer et al., 1995), mitomycin C (Lee et al., 2004; Lee et al., 2006), pimecrolimus (Cemil et al., 2009), absorbable cement (Mehdi et al., 2014), topical high-molecularweight hyaluronan (Kato et al., 2005; Massie et al., 2005; Songer et al., 1990; Chen et al., 2014; Semra et al., 2015) and anti-inflammatory medications (Ross et al., 1996; Cekinmez et al., 2010) have been used with inconsistent results. Therefore, development of a new anti-adhesive material to prevent epidural fibrosis shall benefit spine laminectomy surgery.

Hyaluronic acid (HA), a heteropolysaccharide formed by binding repetitive disaccharide units of D-glucuronic acid and $\mathrm{N}$-acetyl-glucosamine through b-4 bindings, is highly biocompatible and does not cause a foreign-body reaction (Semra et al., 2015). In addition, exogenous HA inhibits foetal fibroblast proliferation and has effective roles in reducing fibrosis and scar formation during the early stages of tissue healing (He et al., 1995). However, HA is water soluble at room temperature and it can only stay in place for a short time. For this reason, it is not suitable in most clinical situations. Compared with HA solution, cross-linked high-molecular-weight $\mathrm{HA}$ is effective in retarding hydrolytic degradation and resides in the tissue for up to $7 \mathrm{~d}$ (Cencetti et al., 2011). In a few animal studies, it reduces epidural fibrosis formation (Chen et al., 2014; Semra et al., 2015). During the proliferative phase of the wound healing process, recruited fibroblasts and newlyproduced extracellular matrix (including collagen and proteoglycan) accumulate at the lesion site and form the granulation tissues before the $3^{\text {rd }}$ week after wound formation. This process, at its highest activity period of four weeks, is critical for the formation of scar tissue that adheres to the apposed tissues (Baum and Arpey, 2005; Lin et al., 2015). Currently available HA derivatives are still far from ideal agents for epidural fibrosis inhibition.

Many researchers and companies have focused on the development of injectable hydrogels for different kinds of tissues (Barbucci et al., 2002; Sakai et al., 2015; Varma et al., 2014; Su et al., 2010). Injectable hydrogels can be maintained in the liquid state before injection and harden in situ after transplantation in vivo. The sol-gel transformation property allows for irregular surgical defects to be completely filled, reducing the risk of material migration. Testing is known of different hydrogels that show effective anti-adhesive behaviour on other tissues, for the prevention of epidural fibrosis. Examples of this are zwitterionic hydrogels on subcutaneous implantation (Zhang et al., 2013) and chitosan dextran gel on abdominal peritoneum (Rajiv et al., 2017). In addition, efforts are made to develop hydrogels with more in situ durability, either by using new materials, such as silk-polyethylene glycol hydrogel (Wang et al., 2015) and poloxamer-based gel (Shin et al., 2016), or by modulating the crosslinking process (Lin et al., 2015). Due to their tuneable physical properties, hydrogels have become versatile tools for drug delivery and combinations of pharmacologic agents and hydrogels are used in epidural adhesion prevention (Lin et al., 2016). In a previous study, we show development of an injectable oxidised hyaluronic acid/adipic acid dihydrazide (oxi-HA/ADH) hydrogel (Su et al., 2010). Since the gelation time of the oxi-HA/ADH hydrogel at $37^{\circ} \mathrm{C}$ is between 143 and $175 \mathrm{~s}$, the change from liquid state into a gel-like matrix occurs within $3 \mathrm{~min}$ after injection into the human body. The hydrogel can maintain the gel-like state for at least 5 weeks, with a percentage degradation in vitro of $40 \%$ under static incubation in phosphate buffered saline (PBS) at $37^{\circ} \mathrm{C}$ and $5 \%$ carbon dioxide (Su et al., 2010). These characteristics make the oxi-HA/ADH hydrogel a good candidate for limiting fibroblast ingrowth at the laminectomy site, from surrounding paraspinal muscles, during the critical period of scar tissue adhesion. The purpose of this study was to test the biocompatibility of this hydrogel for use in spine surgery and to examine the ability of the oxi-HA/ ADH hydrogel to reduce epidural fibrosis, using the rat laminectomy model. Fig. 1 shows the scheme of the experimental setup.

\section{Materials and Methods}

\section{Materials and reagents}

All materials and reagents used in this study were purchased from Sigma-Aldrich (St. Louis, MO, USA) unless otherwise stated. Hyaluronic acid $(\mathrm{MW}=180 \mathrm{kDa})$ was purchased from Q. P. Corporation (Tokyo, Japan).

\section{Preparation of oxidised hyaluronic acid}

$1 \%(\mathrm{w} / \mathrm{v})$ HA was dissolved in double-distilled water at room temperature and then $2.67 \%$ sodium periodate $\left(\mathrm{NaIO}_{4}\right)$ was gently added under stirring. The molar ratio of $\mathrm{NaIO}_{4}$ to HA was $1: 1$. The oxidation reaction proceeded in a dark environment for $2 \mathrm{~h}$ at room temperature. The reaction was stopped by the addition of $0.5 \mathrm{~mL}$ of ethylene glycol. In order to obtain a purified oxidised HA, a Cellu-Sep T-series ${ }^{\circledR}$ dialysis membrane (8030-32; Orange Scientific, Braine-l'Alleud, Belgium) was used to separate the by-product and the oxidised HA. Double-distilled water was used as a dialysis buffer solution and the water was changed three times per day. $1 \%$ silver nitrate $\left(\mathrm{AgNO}_{3}\right)$ was used to check the amount of periodate in the outer dialysis buffer, with water changes required until there was no more precipitate 
visible. The final oxidised HA product was obtained by freeze-drying (FDU-1200; EYELA, Tokyo, Japan). The average yield of oxidised HA was about $87 \%$.

\section{Preparation of hyaluronic acid-ADH hydrogel}

For topical usage at laminectomy sites, PBS solution ( $\mathrm{pH} 7.4)$ was selected as an optimal solvent source. $6 \%(\mathrm{w} / \mathrm{v})$ oxidised HA was dissolved in PBS overnight at $4{ }^{\circ} \mathrm{C}$ and gently mixed with $8 \%(\mathrm{w} / \mathrm{v})$ adipic acid dihydrazide (ADH) to form the oxi-HA/ ADH hydrogel.

\section{Cell cultivation}

Fibroblasts (NIH/3T3; 60008), myoblasts (C2C12; 60083), Schwann cells (RSC96; 60507) and neural cells (PC-12; 60048) were chosen for the cytocompatibility studies of the oxi-HA/ADH hydrogel. RSC96 and PC-12 cells were used to evaluate possible deleterious effects of the hydrogel on spinal cord, dura sac and nerve root; $\mathrm{C} 2 \mathrm{C} 12$ cells to test whether wound muscle healing would be affected; NIH/3T3 cells to measure the epidural fibrosis reduction. All cell lines were purchased from the Bioresource Collection and Research Centre (BCRC, Hsinchu, Taiwan). NIH/3T3, C2C12 and RSC96 were cultured in 90\% high-glucose Dulbecco's modified Eagle's medium (DMEM), supplemented with $4 \mathrm{mM}$ L-glutamine, $10 \%$ foetal bovine serum (FBS, 26140-079; Gibco, Life Technologies, Carlsbad, CA, USA) and $1 \%$ antibiotic (15240-062; Gibco), at $37{ }^{\circ} \mathrm{C}$ in a humid atmosphere containing $5 \% \mathrm{CO}_{2}$. PC-12 were cultured in 85 \% Roswell Park Memorial Institute (RPMI) 1640 medium, supplemented with $2 \mathrm{mM}$ L-glutamine, $10 \%$ heat-inactivated horse serum, $5 \%$ FBS and $1 \%$ antibiotic.

\section{Cytocompatibility of the oxi-HA/ADH hydrogel}

Cytocompatibility of the oxi-HA/ADH hydrogel was evaluated by testing the extraction medium with four different cell lines, according to ISO standards (International Standardisation Organisation, 1992). The extraction medium was prepared by incubating the oxi-HA/ADH hydrogel for $72 \mathrm{~h}$ at $37{ }^{\circ} \mathrm{C}$ with standard culture medium (as described above) at a $0.75 \mathrm{~cm}^{2} \mathrm{~mL}^{-1}$ extraction ratio. $5 \times 10^{3}$ cells (PC-12 and $\mathrm{NIH} / 3 \mathrm{~T} 3$ ) and $2.5 \times 10^{3}$ cells (C2C12 and RSC96) were seeded into a 96-well polystyrene cell culture plate (Advangene Consumables, Lake Bluff, IL, USA) and cultured overnight in standard medium. Then, the culture medium was changed to extraction medium and the cells where cultured for additional $72 \mathrm{~h}$. In order to minimise the effect of the serum, FBS was added into both standard and extraction medium prior to cell seeding. In addition, a serum-free extraction medium group was added. Groups in the study included negative control (standard culture medium), positive control (medium containing $0.1 \%$ Triton X-100), extraction medium, diluted extraction medium (1: 2 dilution) and serum-free extraction medium. Furthermore, fluorescence-based live/dead staining (Molecular Probes, Waltham, OR, USA) was performed on cells cultured in different media/extract to identify cell survival under different conditions.

After been cultured in extraction or standard medium for $72 \mathrm{~h}$, cell viability was evaluated. First, test media were collected and preserved for testing the cytotoxicity. Then, cells were washed twice with PBS and subsequently $0.1 \mathrm{~mL}$ watersoluble tetrazolium-8 (WST-8; Enzo Life Sciences, Farmingdale, NY, USA) working solution was added into each well. After $2 \mathrm{~h}$ incubation, the WST-

\section{\begin{tabular}{|l|l|}
\hline in vitro cytocompatibility & in vivo test in animal laminectomy model \\
\hline
\end{tabular}}

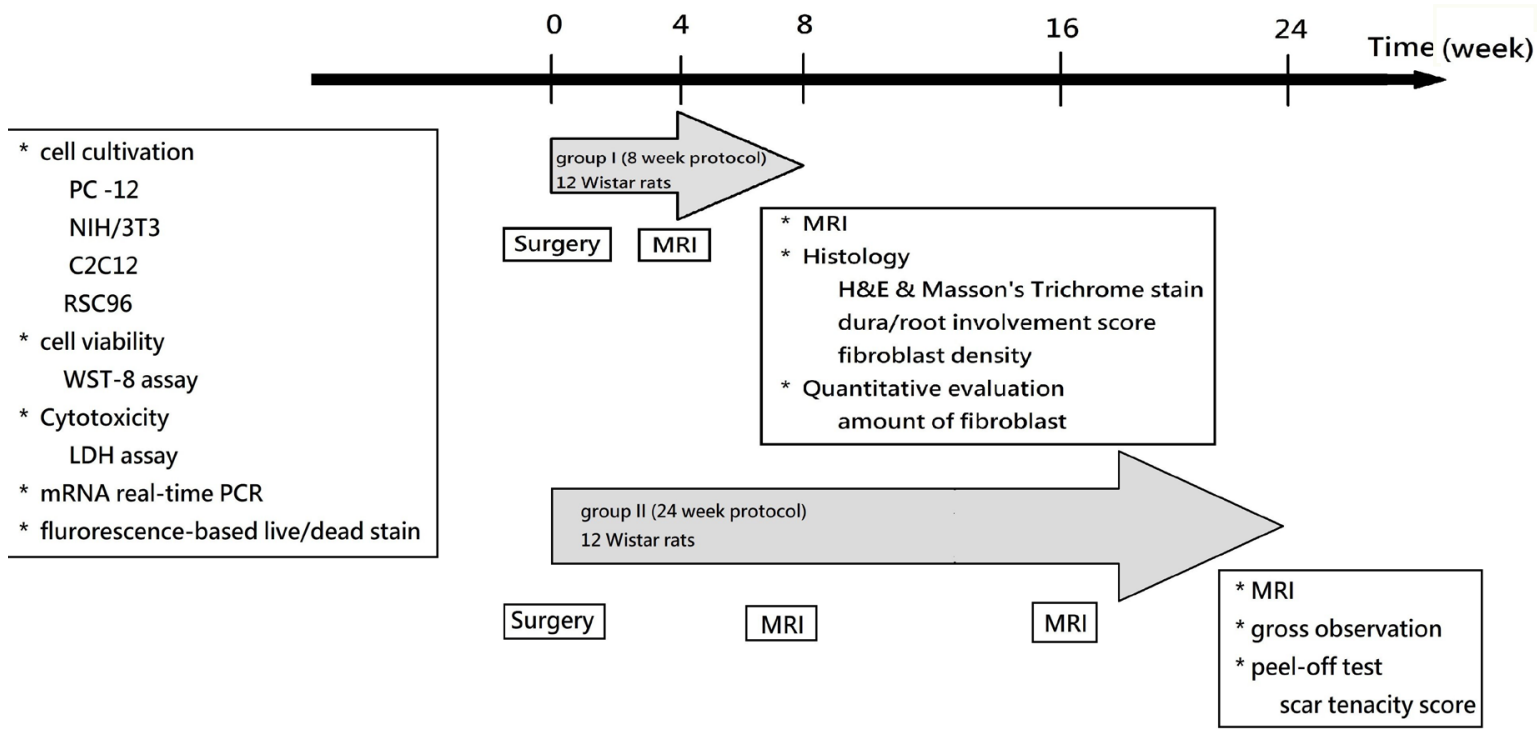

Fig. 1. Scheme of the experimental setup: in vitro cytocompatibility test of the hydrogel was performed first, followed by examination of the effect of the oxi-HA/ADH hydrogel on the reduction of the epidural fibrosis using a rat laminectomy model. 
8 working solution should show a colour change due to cleavage of the tetrazolium salt by cellular mitochondrial dehydrogenase and formation of formazan. Cell viability was quantitatively assessed by spectrophotometer readout at $450 \mathrm{~nm}$, with a reference wavelength at $650 \mathrm{~nm}$.

For cytotoxicity evaluation, $50 \mu \mathrm{L}$ of the incubation medium were transferred into a 96-well ELISA plate, mixed with $50 \mu \mathrm{L}$ of substrate mix and incubated for $30 \mathrm{~min}$ in the dark. The tetrazolium salt in the substrate mix could react with the lactate dehydrogenase (LDH) to give a red formazan product (CytoTox $96^{\circledR}$ Non-Radioactive Cytotoxicity Assay, G1780; Promega, Madison, WI, USA). LDH released was quantitatively assessed by spectrophotometer readout at $490 \mathrm{~nm}$. The extraction media were prepared from three batches of hydrogels and used separately. The extractions were diluted with serumfree medium (volume ratio $1: 1$ ). The toxicity of undiluted and diluted extraction media were tested in four cell types ( $n=4$ for each cell line).

\section{Quantitative real-time polymerase chain reaction}

Cells $\left(2 \times 10^{5}\right.$ cells for C2C12 and RSC96 and $4 \times 10^{5}$ cells for NIH/3T3 and PC12) were suspended in $200 \mu \mathrm{L}$ of the oxi-HA/ADH hydrogel and placed in an incubator for $10 \mathrm{~min}$ for gelation. Then, the cell/ gel constructs were transferred into a 24-well culture plate and $1.5 \mathrm{~mL}$ culture medium was added. For comparison, the same quantity of cells was cultured in monolayer in a 24-well culture plate. After one week of culture, two samples of each culture type were pooled together for analysis of gene expression. Quantitative real-time polymerase chain reaction (qPCR) analysis was performed on pooled samples of both monolayer cultured cells and cells encapsulated within the oxi-HA/ADH hydrogel. Total RNA was extracted using the PureLink ${ }^{\mathrm{TM}}$ Mini RNA kit, according to the manufacturer's instructions (Invitrogen, Carlsbad, CA, USA). During extraction, RNA was treated with RNase-free DNase (Qiagen, Chatsworth, CA, USA) to eliminate any residual DNA. An aliquot of RNA was used to quantify RNA yield by recording the absorbance at $260 \mathrm{~nm}$ with a NanoDrop 2000 UV-Vis spectrophotometer (Thermo Scientific, Wilmington, DE, USA). The reverse transcription (RT) reaction was performed using the High-Capacity cDNA Reverse Transcription Kit (Applied Biosystems, Foster City, CA, USA). Briefly, $10 \mu \mathrm{L}$ of RNA were added to $10 \mu \mathrm{L} 2 \times \mathrm{RT}$ master mix, containing RT buffer, deoxynucleotides (dNTPs) mix, RT random primers and MultiScribe reverse transcriptase. The RT reaction mixture was incubated at $25{ }^{\circ} \mathrm{C}$ for $10 \mathrm{~min}$, then at $37^{\circ} \mathrm{C}$ for $120 \mathrm{~min}$ and finally at $85{ }^{\circ} \mathrm{C}$ for $5 \mathrm{~min}$ to inactivate the enzyme. Complementary DNA, synthesised from $20 \mathrm{ng}$ of RNA, was subjected to PCR amplification using the TaqMan Universal PCR Master Mix and Assayson-Demand Gene Expression probes on an ABI PRISM 7900HT sequence detection system (Applied Biosystems) ( $n=3$ for each cell line). The following expression profiles were examined: $S 100 b$ (a small EF-hand calcium and zinc binding protein, highly expressed in the adult vertebrate nervous system) in PC12 and RSC96 cells; Pax7, Myf6 and Myod1 (transcription factors playing a role in myogenesis and muscle differentiation) in C2C12; S100a4 (a member of the S100 family) and $P 4 h b$ (encoding the beta subunit of the prolyl4-hydroxylase and identified in fibroblast-cell-derived exosomes) in NIH3T3. Glyceraldehyde-3-phosphate dehydrogenase $(G A P D H)$ was used as endogenous control for gene expression. mRNA expression for each of the target genes was normalised to the housekeeping gene $G A P D H$. The $\triangle \mathrm{CT}$ was calculated by subtracting the cycle threshold (CT) of GAPDH from the CT of each target gene. The $\triangle \mathrm{CT}$ for each treated group was further normalised to the monolayer group to obtain the $\triangle \mathrm{CT}$. Relative expression was calculated using the $2^{-\triangle \Lambda C T}$ method.

\section{Surgical procedures}

24 female Wistar rats (3 months old and weighing 350400 g; purchased from BioLASCO Taiwan Co., Ltd; fed at the Laboratory Animal Centre, National Taiwan University College of Medicine, Taipei, Taiwan) were used in this study. Animals were maintained in accordance with the guidelines for the care and use of laboratory animals. Experimental protocols and surgical procedures were approved by the National Taiwan University Hospital College of Medicine Institutional Animal Care and Use Committee (IACUC). Rats were fed with Purina laboratory chow (PMI Nutrition International Certified LabDiet, St. Louis, MO, USA), had access to tap water ad libitum and were housed in a temperature-, humidity- and light-controlled environment. Animals were marked to aid the individual identification and acclimatised in their cages for $28 \mathrm{~d}$ before the start of the study.

Under anaesthesia by intra-abdominal injection of $30 \mathrm{mg} / \mathrm{kg}$ sodium pentobarbital, rats were fixed in a prone position, with skin being disinfected and draped. In each rat, two midline skin incision, approximately $3 \mathrm{~cm}$ in length, were made at the thoracic and lumbar area, separately. The spinous processes were exposed and the paraspinous muscles were dissected bilaterally. Total laminectomy with a longitudinal length of $10 \mathrm{~mm}$ and transverse width of $5 \mathrm{~mm}$ at the L4-L5 level and mid-thoracic level were performed by the same spine surgeon using an operative microscope.

The two laminectomy areas of each rat were assigned one to treatment group and the other to control group, respectively. Treatment and control group between the two spine levels were randomly assigned, considering the anatomical differences between thoracic and lumbar spine. In the treatment group, the dura mater was exposed after the laminectomy and the topical hydrogel $(0.1 \mathrm{~mL})$ was applied at the laminectomy site to cover the entire exposed dura theca and root. In contrast, in the control group, laminectomy was followed by 
no additional procedure (Fig. 2). The wounds were closed layer by layer after attaining haemostatic control.

The 24 Wistar rats were divided into two groups subjected to different protocols.

\section{Preparation of specimens}

4 and 8 weeks after surgery of group I animals (8 weeks protocol), a 7T-magnetic resonance imaging (MRI) (Bruker BioSpec 70/30 MRI; Core Lab of the Neurobiology and Cognitive Science Centre, National Taiwan University, Taipei, Taiwan) was used for morphological evaluation of the fibrotic tissue overlying the exposed dura sac.

8 weeks after surgery, group I animals were euthanised by intraperitoneal administration of a high dose $(75-100 \mathrm{mg} / \mathrm{kg})$ of sodium pentobarbital. The whole thoraco-lumbar spinal column was removed. The specimens were fixed for $2 \mathrm{~d}$ in $10 \%$ buffered formaldehyde solution. Next, they were immersed for $3 \mathrm{~d}$ in a decalcification solution $(0.5 \mathrm{M}$ aluminium chloride, $8.5 \% \mathrm{HCl}$ and $5 \%$ formic acid). Subsequently, $2 \mathrm{~mm}$-thick specimens were cut at the laminectomy site, transverse to the spinal canal. These tissues were processed according to routine tissue-processing techniques. Serial sections of $4 \mu \mathrm{m}$ were cut from paraffin-embedded blocks using a microtome (Leica, Wetzlar, Germany) and stained with haematoxylin and eosin (H\&E) and Masson's trichrome kits (Polysciences, Warrington, PA, USA).

\section{Histopathological examination}

All tissue samples were evaluated by a blinded observer. Using a light microscope, each section was evaluated and scored for the extent of fibrosis, dura adhesion and density of fibroblasts. The dura adhesion parameters were evaluated according to the criteria proposed by $\mathrm{He}$ and colleagues, already proved to have good inter-rater reliability (He et al., 1995; Sae-Jung et al., 2015). Fibroblast cell density was calculated in each field at $40 \times$ magnification, following the classification system proposed by
Hinton et al. (2015), according to which the definition of grade 1 was fewer than 100 fibroblasts in each field, grade 2 100-150 fibroblasts in each field and grade 3 more than 150 fibroblasts in each field. The number of fibroblasts was counted and the average recorded for all 12 rats (2 laminectomy level in each rat, with one being treatment group and the other control group), repeating the procedure for three fields per sample (one from the middle of the laminectomy area and two from the margins, one on each side). The cell counting resulting for each group was expressed in cell number per $\mathrm{mm}^{2}$ (Tao and Fan, 2009).

\section{Superficial observation and peel-off testing}

8,16 and 24 weeks after surgery of group II animals (24 weeks protocol), 7T-MRI images were acquired. 24 weeks after surgery, the rats were sacrificed, as described above. Using forceps, the scar tissue was peeled off manually. The tenacity of adhesion between the scar tissue and dura mater was evaluated and the difficulty of separating the scar from the dura mater was also taken into consideration. A six-level scoring system (grades 0-5) was used to indicate the separation difficulty. Grade 0 indicated no adhesion between the dura and scar tissue; grade 1, very slight adhesion to the dura mater and tissue easily detachable without applying manual force; grade 2 , some adhesion to the dura and the tissue easily detachable by moderate traction; grade 3 , less than $50 \%$ of the operated area had adhesion and could be detached by strong traction; grade 4 , more than $50 \%$ of the operated area had adhesion and could be bluntly detached by strong traction; grade 5 , severe adhesion not detachable without disruption of the dura mater, unless sharp dissection was used (Einhaus et al., 1997). The result of the scoring was defined as the dura/root involvement score.

\section{MRI}

Spinal coil T2-weighted MRI images were acquired in transverse plane $(\mathrm{TR}=3000 \mathrm{~ms}$, $\mathrm{TE}=26.7 \mathrm{~ms}$, slice thickness $=1 \mathrm{~mm}$ ) with a $7.0 \mathrm{~T}$ sigma MRI instruments
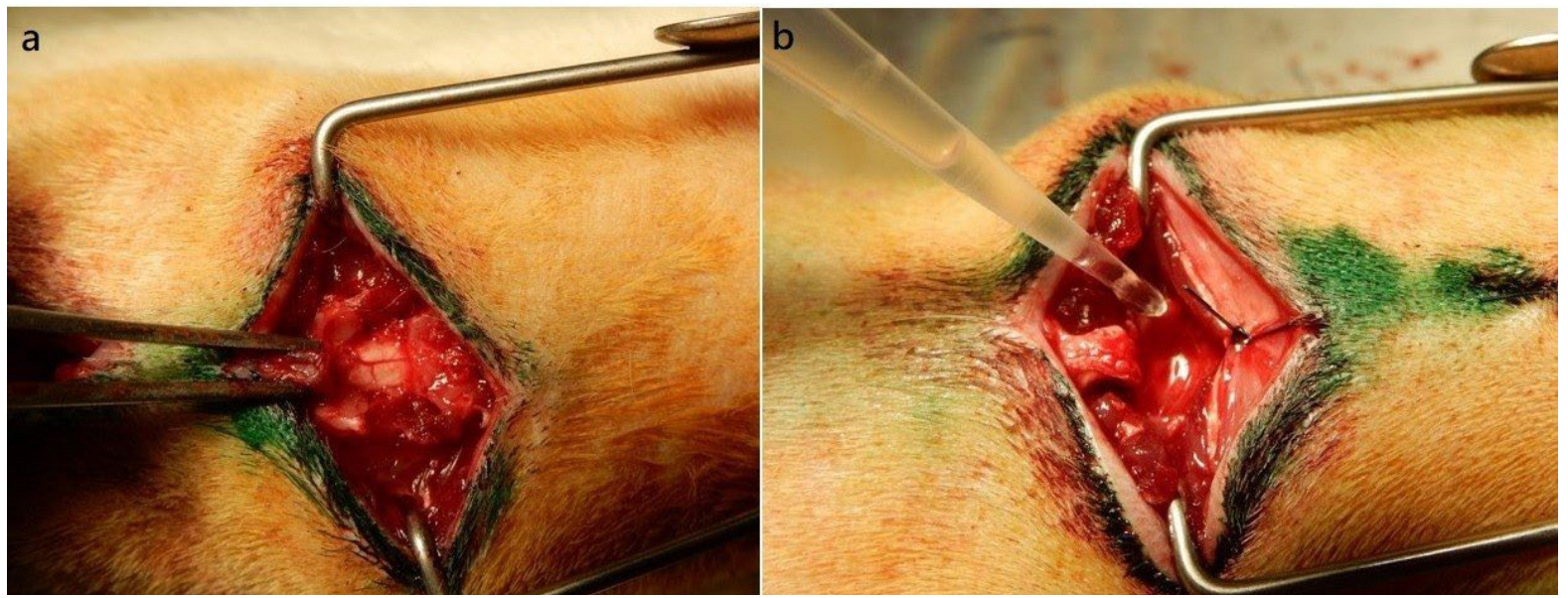

Fig. 2. Images of surgery. (a) In control group, only laminectomy was performed without any additional procedures; (b) in treatment group, after laminectomy, the topical hydrogel was applied at the laminectomy site to cover the entire exposed dural theca and root. 
(Bruker BioSpec 70/30 MRI) using a standard phase array. The MR images were used for measuring the area of scar adhesion.

\section{Statistical analysis}

All data were represented as means \pm standard error of the mean (SEM). Wilcoxon matched-pairs signed ranks test was used for comparison of control vs. treatment group. Statistical significance was considered at $p<0.05$.

\section{Results}

\section{Cytocompatibility of the oxi-HA/ADH hydrogel}

$3 \mathrm{~d}$ after cultivation of the 4 different cell lines with the test media, cell viability and cytotoxicity were evaluated by WST-8 and LDH assays, respectively. As shown in Fig. 3a, the WST-8 optical density (OD) at $450 \mathrm{~nm}$ for PC-12 cells cultivated in extraction medium, diluted extraction medium and standard medium was $0.148 \pm 0.017,0.196 \pm 0.027$ and $0.196 \pm 0.052$, respectively. For NIH/3T3 cells, extraction medium, diluted extraction medium and control medium ODs were $0.477 \pm 0.011,0.547 \pm 0.007$ and $0.569 \pm 0.01$, respectively. When compared to cells cultured in standard medium, extraction medium caused a relatively lower viability $(p<0.05)$ in PC12 and NIH/3T3 cells. Although NIH/3T3 cells in diluted extraction medium had a lower viability $(p<0.05)$ compared to standard medium, there was no significant difference between these two groups and PC-12 cells. For C2C12 cells, extraction medium, diluted extraction medium and standard medium ODs were $0.254 \pm 0.083,1.203 \pm 0.059$ and $1.487 \pm 0.101$, respectively and for RSC96, they were $1.028 \pm 0.067,1.669 \pm 0.124$ and $2.166 \pm 0.148$, respectively. In the four different cell lines, extractionmedium-cultivated cell had lower absorbance values compared to cell cultivated in standard medium and diluted extraction medium. Moreover, although the cell activity in extraction medium was lower than that in standard medium, the cell viability was still higher compared to cell cultivated in positive control medium and serum-free extraction medium.

Additionally, the LDH OD at $490 \mathrm{~nm}$ showed no significant differences among cells cultivated in extraction medium, diluted extraction medium and standard medium. A significantly higher LDH OD at $490 \mathrm{~nm}(p<0.05)$ was observed in positive control compared to the other 3 groups (extraction medium, diluted extraction medium and standard medium) for PC12, NIH/3T3 and RSC96 (Fig. 3b).

In a fluorescence-based live/dead staining, similar cell numbers and survival rates were found for PC12, $\mathrm{NIH} / 3 \mathrm{~T} 3$ and RSC96 cells cultivated in extraction medium, diluted extraction medium and standard medium (Fig. 4). However, for C2C12 cells, lower cell density and more dead cells were found in the extraction medium (Fig. 4j) compared to diluted extraction medium (Fig. 4k) and standard medium (Fig. 41).

\section{mRNA gene expression}

To evaluate the specific gene expression of the four different cell lines cultured as monolayer or encapsulated within the oxi-HA/ADH hydrogel, a qPCR analysis was performed following $7 \mathrm{~d}$ of cultivation. $S 100 b$ mRNA level $(0.967 \pm 0.62)$ in PC12 cells cultivated in the oxi-HA/ADH hydrogel was equal to that of the monolayer culture. However, S100b expression $(3.865 \pm 0.23, p<0.05)$ was significantly up-regulated in RSC96 cells cultivated in the oxi-HA/ADH hydrogel, compared to the monolayer culture (Fig 5a). S100a4 (0.079 \pm 0.005, $p<0.05)$ and $P 4 h b(0.087 \pm 0.006, p<0.05)$ gene expressions were significantly down-regulated when NIH/3T3 cells were cultured in the oxi-HA/ a

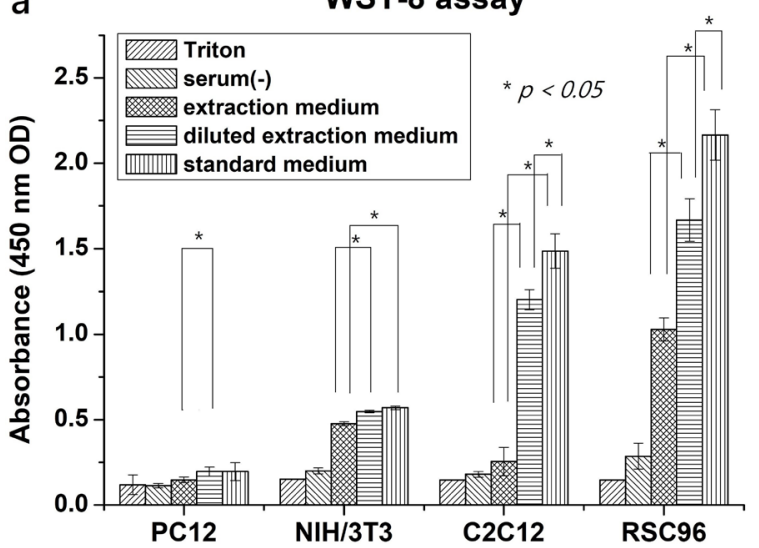

b

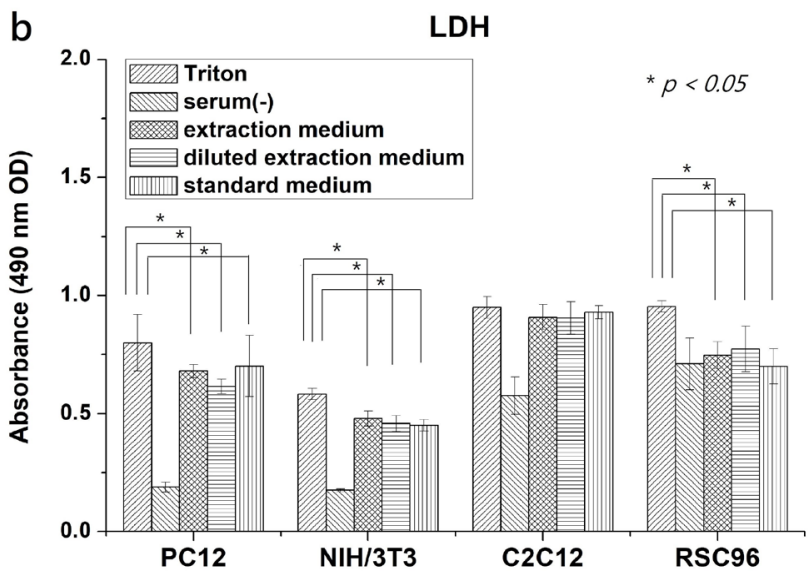

Fig. 3. Cytocompatibility of the oxi-HA/ADH hydrogel. Diluted extraction medium $(1: 2)$ and serumfree extraction medium were tested, whereas $0.1 \%$ Triton-X-100-containing medium was used as a positive control. (a) When compared with the cells cultured in the standard medium, the extraction medium caused a relative lower viability $(p<0.05)$ in PC-12 and NIH/3T3 cells. In the 4 different cell lines, extraction medium had lower absorbance levels when compared to standard medium and diluted extraction medium. (b) LDH OD at $490 \mathrm{~nm}$ showed no significant difference between extraction medium, diluted extraction medium and standard medium. 
ADH hydrogel. Similarly, down-regulations of $\operatorname{Pax} 7$ $(0.159 \pm 0.003, p<0.05)$, Myf6 $(0.166 \pm 0.037, p<0.05)$ and Myod1 $(0.088 \pm 0.084, p<0.05)$ mRNA levels were observed when $\mathrm{C} 2 \mathrm{C} 12$ cells were encapsulated within the oxi-HA/ADH hydrogel (Fig 5b).

\section{Surgical outcome}

All rats included in this study could walk after surgery, without any obvious neurological problems. Skin, fascia and muscle around the surgical sites healed well in both group I and II and no infection, local swelling or discharge from the wound was noted at sacrifice.

\section{Histological analysis}

Significant differences $(p<0.05)$ were observed between group I and II regarding epidural fibrosis, dura adhesion and fibroblast cell density (Fig. 6a). The mean of the dura/root involvement score for the extent of scar adhesion was significantly lower in hydrogel group (1.17. \pm 1.17$)$, compared to control group $(2.33 \pm 0.52)(p<0.05)$ (Fig. 6a). Furthermore, variable grades of epidural fibrosis were observed in the rats of both groups. However, microscopical examination showed that the tissue treated with hydrogel presented more discontinuous areas of hypointense signals between the dura mater and the surrounding scar tissue and a smaller number of inflammatory cells in the scar tissue at both thoracic and lumbar laminectomy site (Fig. 7). The thickness of the epidural scar tissue was relatively wider in control group, which was also shown in the MRI sequence, whereas the MRI showed a relatively loose epidural tissue in hydrogel group, 24 weeks after the surgery (Fig. 8). In addition, in both groups, a time-dependent correlation of scar tissue thickness was found, with the scar being thicker at 24 weeks compared to 8 weeks after surgery.

The density of fibroblast cell score was significantly less in the hydrogel group with $1.33 \pm 0.52$, whereas the mean was $2.33 \pm 0.52$ in the control group $(p=0.004)$ (Fig. 6a).

\section{Superficial observation and peel-off test}

Superficially, no residual hydrogel could be seen at sacrifice in all rats of the treatment group. Three rats were scored as grade 1, with no adhesion between the dura and scar tissue, which were easily separable (Fig. 6b). The exposed dura after revision surgery were surprisingly smooth. Oppositely, in the control group, all rats scored 3 or more, with disruption of the dura mater in one animal.

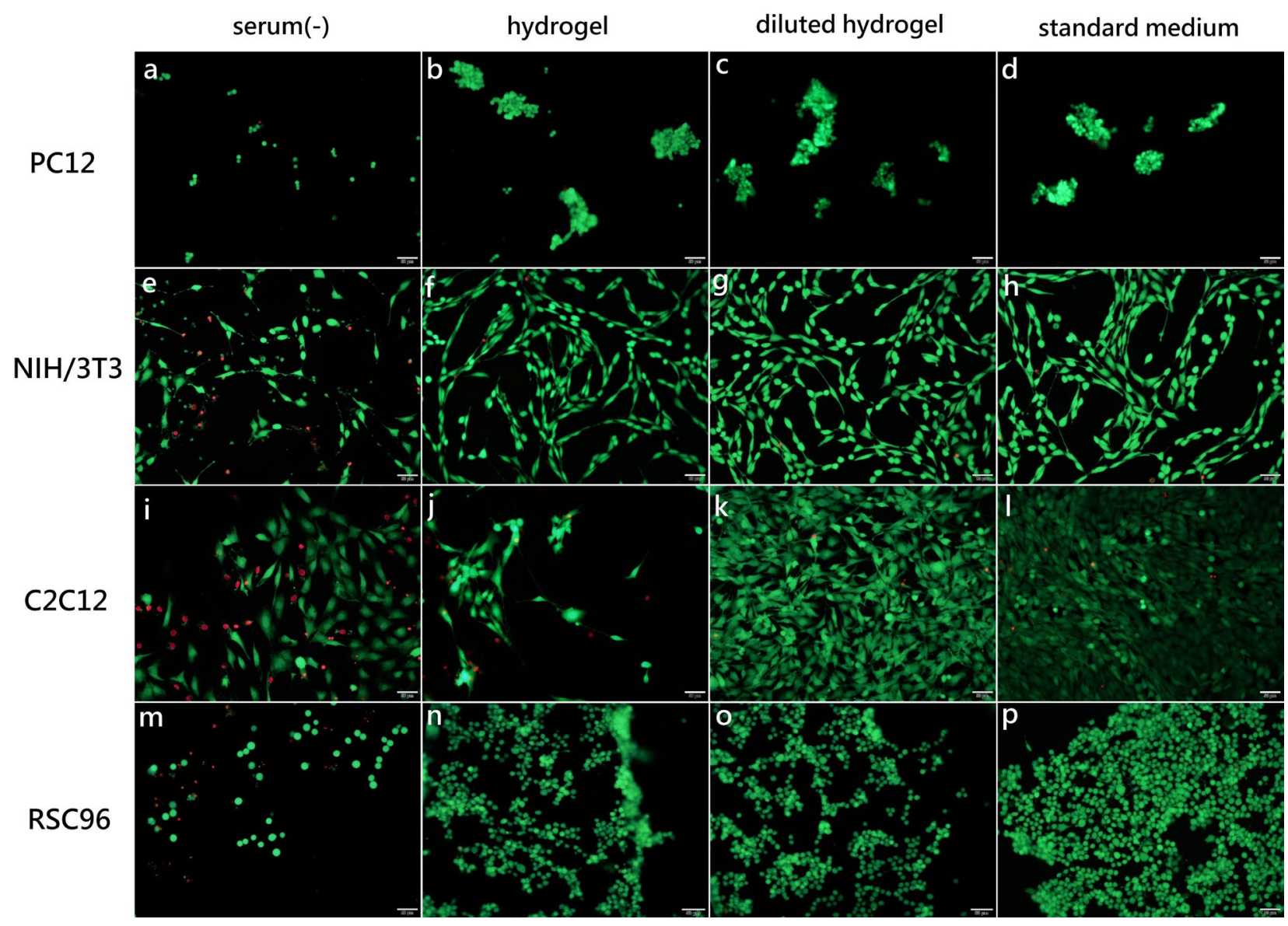

Fig. 4. Fluorescence-based live/dead staining for (a-d) PC12, (e-h) NIH/3T3, (i-1) C2C12 and (m-p) RSC96. Similar cell numbers and survival rates were observed for PC12, NIH/3T3 and RSC96 cells cultivated in extraction medium, diluted extraction medium and standard medium. For C2C12 cells, a relative smaller cell number and lower survival rate were observed when cells were cultured in (j) extraction medium compared to (k) diluted extraction medium and (1) standard medium. Scale bar $=50 \mu \mathrm{m}$. 
In manual peel-off testing, the mean grade were $4 \pm 0.63$ for the control group and $1.67 \pm 0.82$ for the treatment group (Fig. 7). The tenacity of the adhesion between the scar tissue and dura was significantly different in the two groups $(p<0.0001)$.

\section{Quantitative histology evaluation: number of fibroblasts}

8 weeks postoperatively, the number of fibroblasts was significantly larger in the control group compared to treatment group. The average fibroblast number in the control group was 1,916 \pm 546 per $\mathrm{mm}^{2}$ and the average fibroblast number in the treatment group was 1,106 \pm 176 per $\mathrm{mm}^{2}(p=0.026)$ (Fig. 9).

\section{Discussion}

Post-operative epidural fibrosis is a normal biological response after laminectomy, which will result in post-laminectomy dura adhesion. The origins of postoperative fibrosis are multifactorial and the effects of the unavoidable fibrotic tissue formation

a

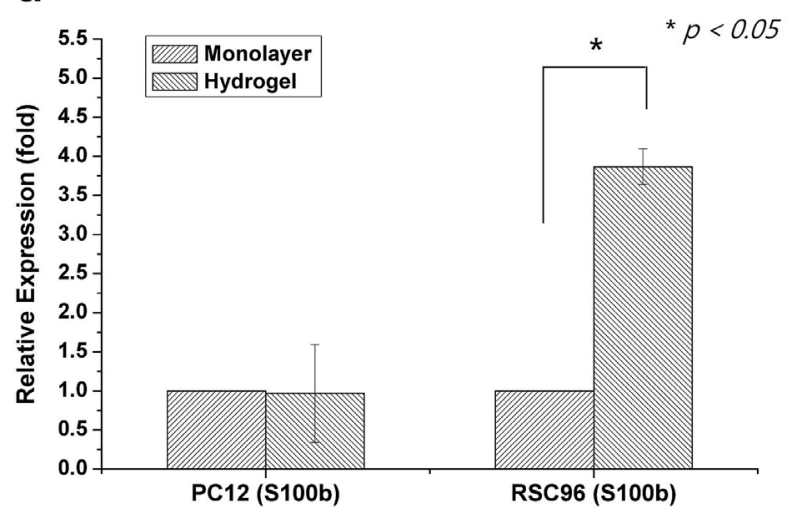

on postoperative pain are not fully understood (He et al., 1995). In fact, fibrosis and adhesion are the results of an inflammatory reaction, an inevitable process during tissue healing, and are caused by the organisation of the fibrin matrix (Chen et al., 2014). Several mechanisms have been proposed to explain the presence of post-laminectomy dura adhesion. LaRocca and colleagues have concluded that fibrosis originates from the posterior invasion of fibroblasts, extending from the erector spinae muscle to the dura and then growing into the haematoma (LaRocca and MacNab, 1974). Accordingly, Holtz suggests an approach that could possibly decrease the fibrosis formation, including separation of fibrin by a physical barrier and inhibition of fibroblast proliferation (Holtz, 1980). Based on this theory, a variety of biological, pharmacological and synthetic materials have been tested since LaRocca and MacNab first designated the laminectomy membrane in 1974 (LaRocca and MacNab, 1974).

HA, a highly biocompatible heteropolysaccharide, is widely used in the biomedical field. HA reduces foetal fibroblast proliferation and effectively inhibits fibrosis and scar formation during the early stages

b

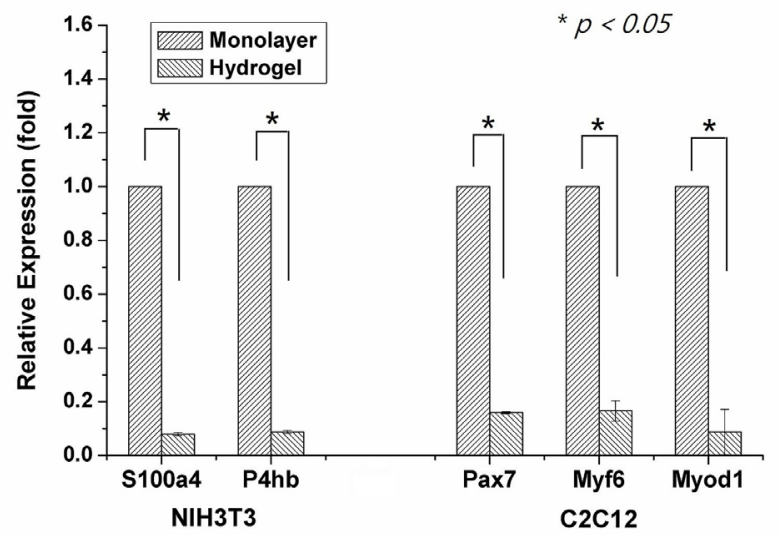

Fig. 5. (a,b) Gene expression in fibroblast cell (NIH/3T3), myoblast cell (C2C12), Schwann cell (RSC96) and neural cell (PC 12) cultivated as monolayer and encapsulated within the oxi-HA/ADH hydrogel, including S100b for PC12 and RSC96, S100a4 and P4hb for NIH/3T3 and Pax7, Myf6 and Myod1 for C2C12.
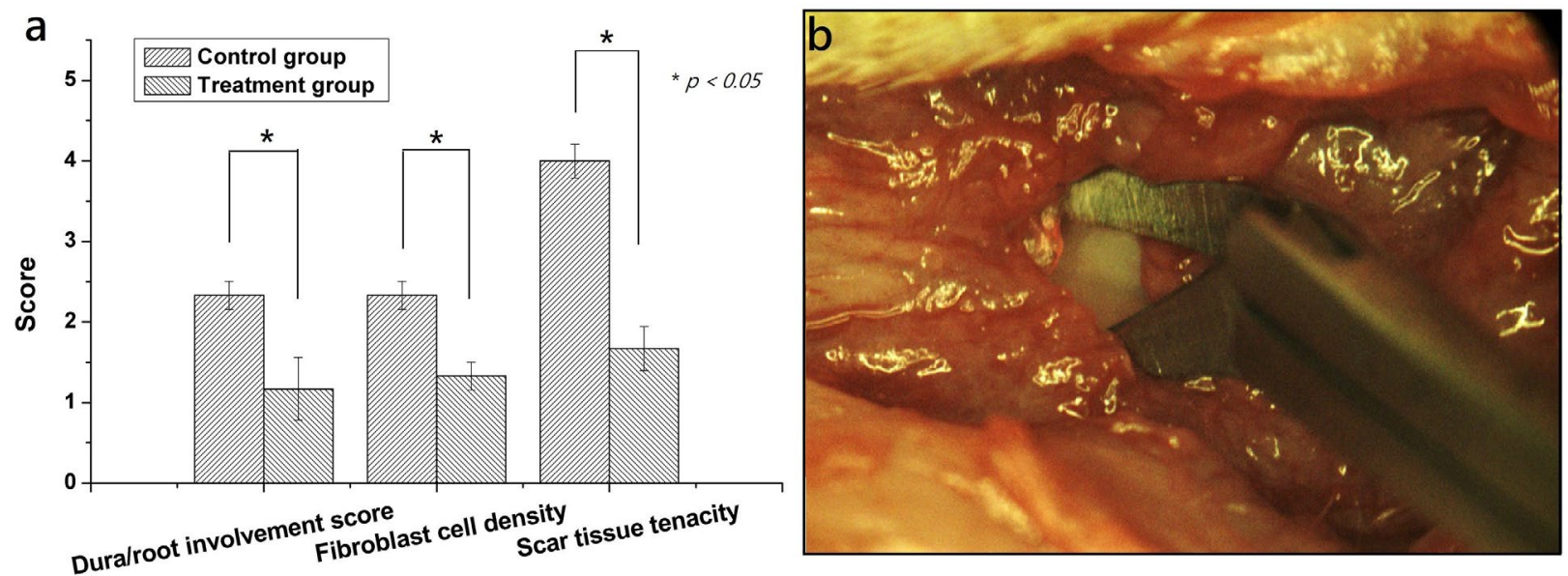

Fig. 6. (a) Epidural fibrosis, dura adhesion, fibroblast cell density and peel-off test were significantly different between control and treatment groups $(n=12)$. (b) Superficially, no residual hydrogel at sacrifice was observed in all rats of the treatment group. Dura and scar tissue were easily separated at previous laminectomy site, which was covered with the oxi-HA/ADH hydrogel. 
of tissue healing (He et al., 1995; Semra et al., 2015). Recently, it has been used as an anti-adhesive material in other surgical fields, such as different kinds of intra-abdominal surgeries (Yeo et al., 2007; Huberlant et al., 2015), ophthalmology surgeries (Yaacobi et al., 1992) and post-surgery tendon adhesions (Liu et al., 2008; Kaux et al., 2016). Recently, HA, including HA solutions and cross-linked high-molecular-weight HA gels, have drawn researchers' attention for the prevention of post-laminectomy epidural fibrosis (Kato et al., 2005; Chen et al., 2014; Semra et al., 2015; Shih et al., 2004). Semra et al. (2015) show that cross-linked high-molecular-weight HA (HA gel) has positive effects on the prevention of epidural fibrosis and reduction of fibrotic tissue density. However, no statistically significant differences are detected between HA and HA gel in either the histopathological evaluation or the biochemical analysis (Semra et al., 2015). Compared to HA, HA gel effectively retards hydrolytic degradation and remains longer in the tissues. However, it is still resorbed through HA's pathways within $7 \mathrm{~d}$, which could be too short to overcome active healing process (Cencetti et al., 2011). Likewise, Chen et al. (2014) conclude that HA-based gelatine may be effective in preventing post-laminectomy dura adhesion in a rabbit animal study. This HA-based gelatine shows positive effects on the prevention of dura adhesion.
However, to date, there is still no solid conclusion regarding an ideal material to be clinically used for the prevention of epidural adhesion.

Due to the complicated procedure of a spine surgery, two major issues need to be solved. First, the implanted barrier with an anti-adhesion purpose may migrate somewhere else. Kato et al. (2005) find that, compared to an HA solution, an HA sheet forms a more solid interpositional barrier and exhibits better anti-inflammatory effects. Moreover, an HA sheet can easily cover the whole exposed nerve structure, and, unlike liquid solutions, it can remain in situ instead of migrating. However, the sheet is not an optimal form during surgery. For surgeon and patient, it could be time consuming to cut the surgical sheet to match the shape of an irregular laminectomy site for a full dura coverage during operation. Second, the biodegradation/bioresorption time of the antiadhesive material in surgical site must be considered. A cross-linked high-molecular-weight HA resides in the tissue for about $7 \mathrm{~d}$ (Cencetti et al., 2011). By using different cross-linking agents, Hahn et al. (2007) report that the degradation time of a HA hydrogel can be extended up to $29 \mathrm{~d}$. However, the degradation time of these HA-based materials is far from ideal for epidural fibrosis inhibition. In general, the highest activity of fibrous connective tissue ingrowth will last for 4-6 weeks.

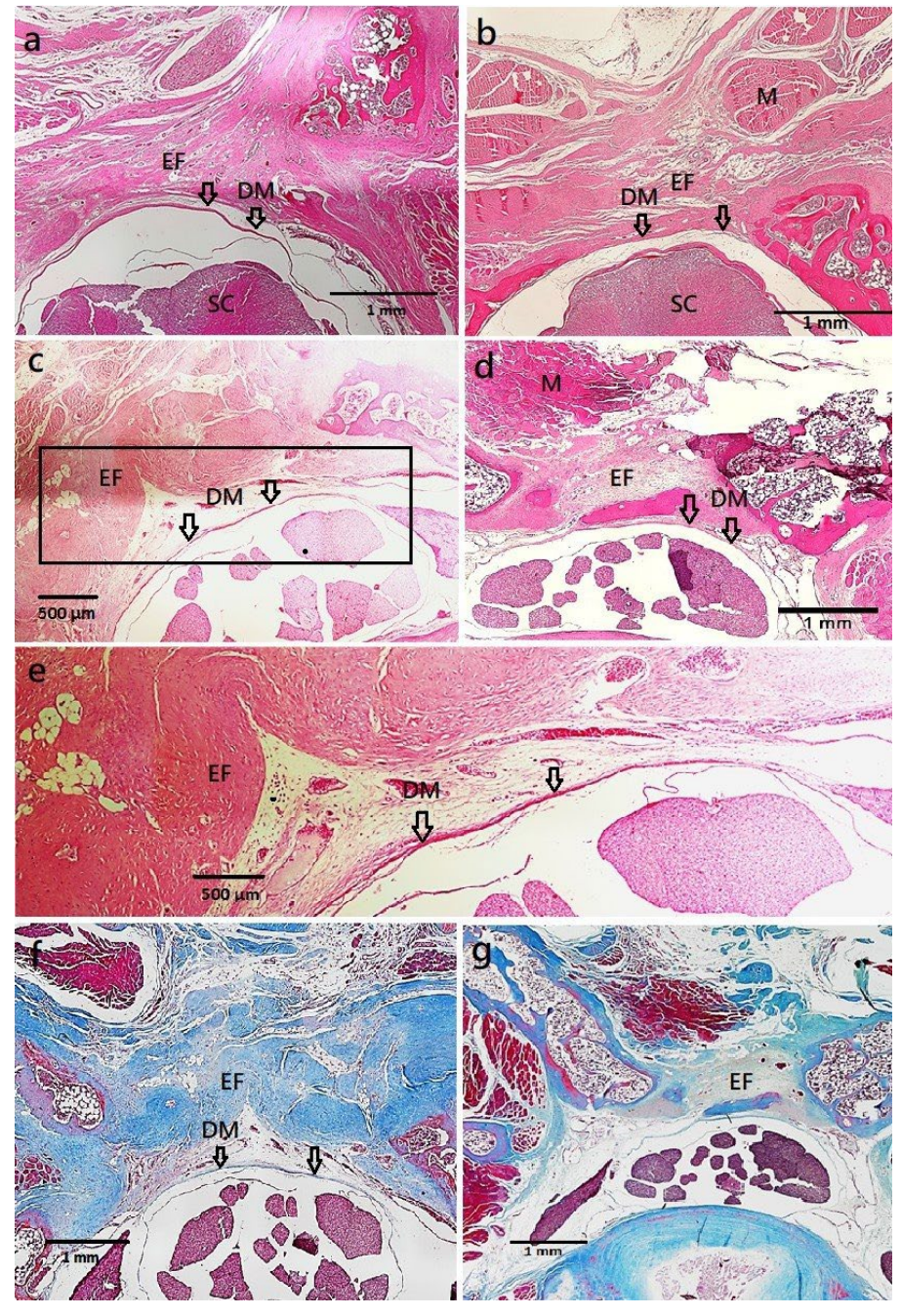

Fig. 7. Histology results 8 weeks postoperatively. (a) 100× magnification image of tissue treated with hydrogel and stained with H\&E at thoracic spine. Only thin fibrosis bands between the epidural fibrotic scar tissues and the dura mater, compatible with grade 1 adhesions, were observed. (b) 100× magnification image of control group tissue stained with H\&E at thoracic spine. Scar adhesion was large and involved more than two-thirds of the laminectomy defect, compatible with grade 3 adhesions. In addition, reduction of dura mater with spinal cord compression was found. 100× magnification images of tissue treated with hydrogel and stained with (c) H\&E and (f) Masson's trichrome showed grade 0 adhesions, with the dura mater free from scar tissue. The rectangle in $\mathbf{c}$ indicated the area represented in $\mathbf{e}$, in which fibroblast density was low and a larger distance from the dura to scar tissues was found. Also, normal muscular structure with some post-surgical fibroblast infiltration of retracted muscle was observed. It showed good muscle and soft tissue healing at the surgical site. (d,g) Control group at lumbar spine showed dominant fibroblast formation (grade 3), with severe adhesion between dura and epidural fibrosis [EF: epidural fibrosis; DM (arrow): dura matter; SC: spinal cord; M: paraspinal muscle]. 
An injectable hydrogel could solve these problems. The hydrogels with a sol-gel transformation property could completely fill the desired region, reduce the risk of migration and lessen the infection rate at the wound site. In the present study, an in situ cross-linked oxi-HA/ADH hydrogel was used and it could be kept in the liquid state for up to $8 \mathrm{~min}$ and transformed into a gel-like matrix within $3 \mathrm{~min}$. This handling property allows surgeons to have sufficient time to prepare and apply this hydrogel during surgery. Since the gelation time is short and the viscosity of the hydrogel is high, the risk of ectopic leakage is supposedly low. From the results of our in vitro/in vivo studies, as well as other groups' reports, the hydrogel should be biocompatible. However, it was noticed that the concentration of extraction medium from the hydrogel may affect the mitochondrial activity of $\mathrm{C} 2 \mathrm{C} 12$ and RSC96 cells. The PCR results showed that three specific gene markers were decreased in $\mathrm{C} 2 \mathrm{C} 12$ cells encapsulated within the oxi-HA/ADH hydrogel, while the viability was also influenced when the cells were cultured in the hydrogel extraction medium. On the other hand, according to the findings of live/dead staining, similar cell number and survival were found when RSC96 where cultured in extraction medium, diluted extraction medium and standard medium. Instead, a smaller cell number was found for $\mathrm{C} 2 \mathrm{C} 12$ cultured in hydrogel extraction medium. Therefore, the possible effect of hydrogel on muscle cells should be further addressed. Although in vivo toxicity testing might provide solid evidence to identify whether the material does harm normal tissue or not, in vitro tests can also reveal possible toxicity at the cellular level. In this study, there was no clinical sign of toxicity, i.e. abnormal animal body weight and food consumption, in the rats treated with the hydrogels. All of the rats showed normal vitality and no rat died during dosing or observational periods. Furthermore, skin, fascia and muscle around the surgical sites healed well. In addition, no infection, local swelling or discharge from the wound was noted at sacrifice. The histology results also demonstrated healthy and well-healed paraspinal muscular structure.

The present study showed that the oxi-HA/ADH hydrogel was an effective and safe anti-adhesion material. It was associated with a reduction of scar tissue, as well as, the degree of adhesion between scar tissue and dura mater. In addition, superficial observation and peel-off test, mimicking the revision surgery that most clinical surgeons are concerned about, showed significantly decreased tenacity at sacrifice, 24 weeks post-operatively. In addition, preventing migration of fibroblasts at the surgical level is a theoretically applicable measure to reduce epidural fibrosis, since fibroblasts are important for the formation of peridural fibrosis originating from the para-spinal muscles. In the present study, we found significantly smaller fibroblast number in the hydrogel group compared to control group. It was hypothesised that our oxi-HA/ADH hydrogel was a biocompatible material, which might induce a reduced inflammatory response.

In clinical practice, an appropriate sterilisation of the materials is another concern. Among the various sterilisation methods, the simplest one is the passage
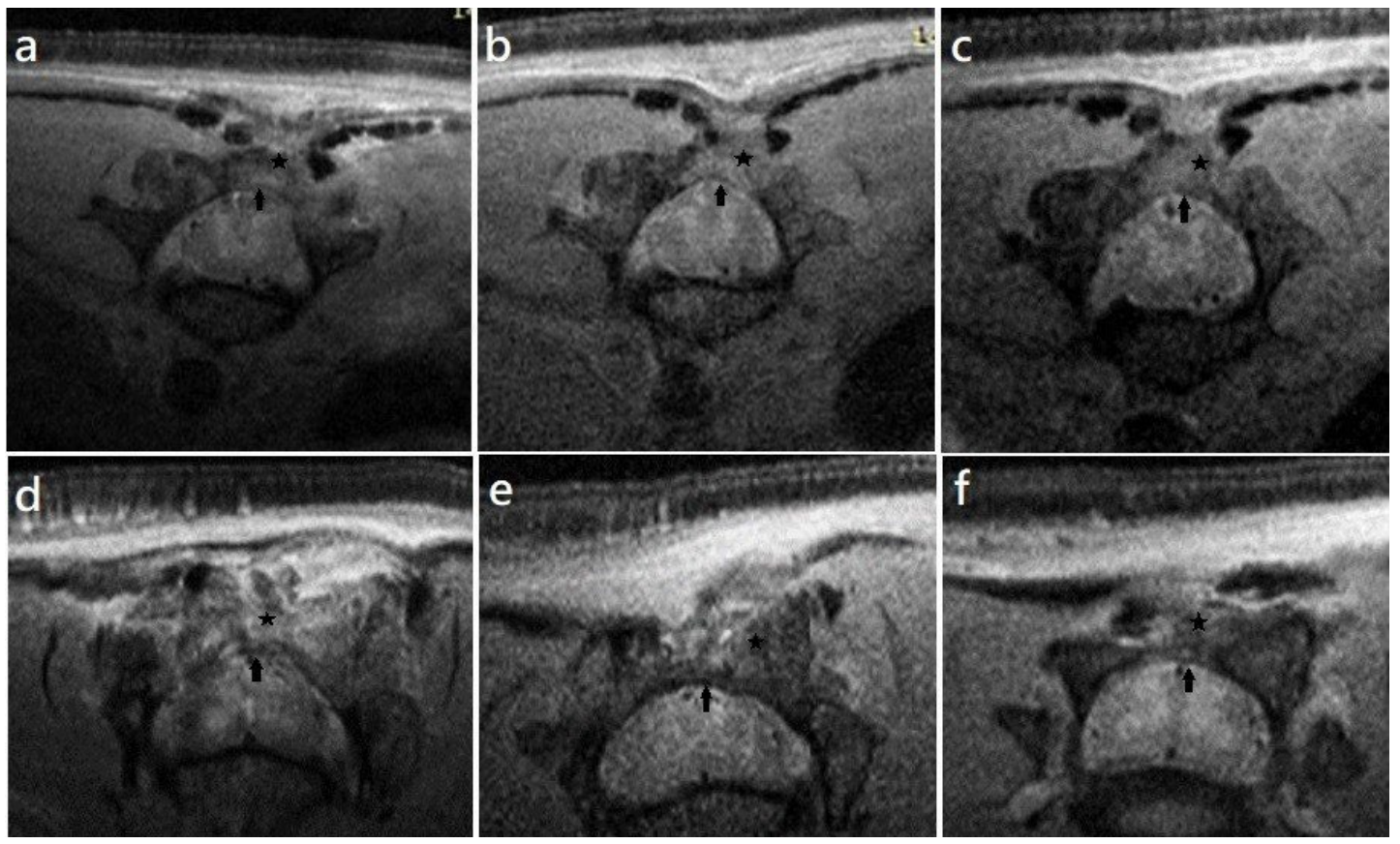

Fig. 8. T2-weighted MRI. (a-c) Control group: 8, 16 and 24 weeks, respectively. A thick layer of epidural fibrotic tissue with dura connection was found. (d-f) Hydrogel group: 8, 16, 24 weeks, respectively. The epidural fibrosis was relatively loose and thin and limited dura contact was found. Moreover, in both groups, a time-dependent correlation of scar tissue thickness was found, with the scar being thicker 24 weeks compared to 8 weeks after surgery (star: epidural fibrosis; black arrow: dura). 

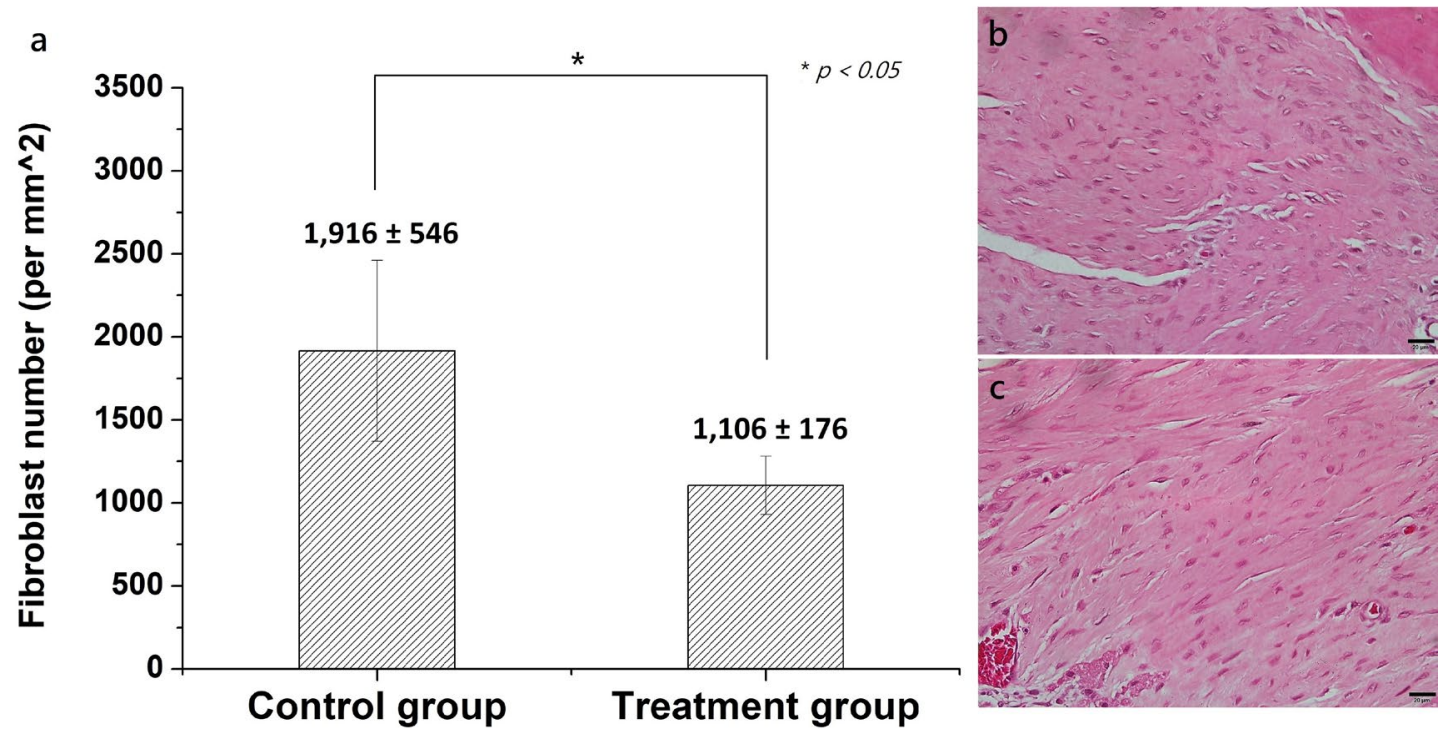

Fig. 9. (a) Fibroblasts number per $\mathrm{mm}^{2}$ of scar tissue, 8 weeks postoperatively $(n=12$, mean \pm SD). (b) The control group showed significant larger number of fibroblasts in epidural scar tissue in comparison with (c) treatment group. The average fibroblast number of control group was 1,916 \pm 546 per $\mathrm{mm}^{2}$ and the average fibroblast number of treatment group was 1,106 \pm 176 per $\mathrm{mm}^{2}$ ( $p$ value indicated control group versus treatment group; $\left.{ }^{*} p<0.05\right)$. Scale bar in $b, c=20 \mu \mathrm{m}$.

of the solution through a $0.22 \mu \mathrm{m}$ filter. It is not easy for native HA to pass through a $0.22 \mu \mathrm{m}$ filter due to its high viscosity, but the viscosity significantly decreases after the oxidation process. For our oxi$\mathrm{HA} / \mathrm{ADH}$ hydrogel, we were able to sterilise the oxi-HA and ADH solutions separately by passaging through a $0.22 \mu \mathrm{m}$ filter (Barbucci et al., 2002). Another advantage of the oxi-HA/ADH hydrogel was that we could mix therapeutic agents with the liquid state $\mathrm{HA} / \mathrm{ADH}$ solution and inject it at the surgical site. Since reduction of the initial inflammatory reaction and exudation could be a possible way for reducing fibrosis (Kato et al., 2005), developing a drug-eluting hydrogel mixed with some anti-inflammatory or fibrolytic agents may be a potential future work.

\section{Conclusion}

In order to prevent post-operative epidural fibrosis after laminectomy, the use of the injectable oxi-HA/ $\mathrm{ADH}$ hydrogel as an anti-fibrotic adhesion barrier was suggested. Based on the experimental findings, the hydrogel had reasonable biocompatibility for neural cells, Schwann cells, fibroblasts and myoblasts. In a rat study, it showed a good sol-gel transformation property, so that it could be handled composedly and easily in order to cover the exposed neural structure in the laminectomy site. Also, it showed good antiadhesive characteristics based on MRI, histology and peel-off tenacity test. In conclusion, the oxi-HA/ADH hydrogel was an effective and promising material in the prevention of epidural fibrosis after spine surgery. Nevertheless, the efficacy of this agent should be further explored in additional experimental and clinical studies.

\section{Acknowledgments}

Authors would like to thank the Taiwanese Ministry of Science and Technology for the financial support (Grant number: NSC 102-2314-B-002-043 -MY2) and the 7T animal MRI Core Lab of the Neurobiology and Cognitive Science Centre of the National Taiwan University for technical and facility supports. We would like to acknowledge the service provided by the Research Core Facilities Labs of the Department of Medical Research at National Taiwan University Hospital.

\section{References}

Alkalay RN, Kim DH, Urry DW, Xu J, Parker TM, Glazer PA (2003) Prevention of postlaminectomy epidural fibrosis using bioelastic materials. Spine (Phila Pa 1976) 28: 1659-1665.

Barberá J, Gonzalez J, Esquerdo J, Broseta J, BarciaSalorio JL (1978) Prophylaxis of the laminectomy membrane. An experimental study in dogs. J Neurosurg 49: 419-424.

Barbucci R, Lamponi S, Borzacchiello A, Ambrosio L, Fini M, Torricelli P, Giardino R (2002) Hyaluronic acid hydrogel in the treatment of osteoarthritis. Biomaterials 23: 4503-4513.

Baum CL, Arpey CJ (2005) Normal cutaneous wound healing: clinical correlation with cellular and molecular events. Dermatol Surg 31: 674-686.

Burton CV (1991) Causes of failure of surgery in the lumbar spine: 10 year follow-up. Mt Sinai J Med 58: $183-187$.

Cekinmez M, Sen O, Atalay B, Erdogan B, Bavbek M, Caner H (2010) Effects of methyl prednisolone 
acetate, fibrin glue and combination of methyl prednisolone acetate and fibrin glue in prevention of epidural fibrosis in a rat model. Neurol Res 32: 700-705.

Cemil B, Tun K, Kaptanoglu E, Kaymaz F, Cevirgen B, Comert A, Tekdemir I (2009) Use of pimecrolimus to prevent epidural fibrosis in a postlaminectomy rat model. J Neurosurg Spine 11: 758-763.

Cencetti C, Bellini D, Longinotti C, Martinelli A, Matricardi P (2011) Preparation and characterization of a new gellan gum and sulphated hyaluronic acid hydrogel designed for epidural scar prevention. J Mater Sci Mater Med 22: 263-271.

Chen JM, Lee SH, Tsai TT, Niu CC, Chen LH, Chen WJ (2014) Anti-adhesive effect of hyaluronate in a rabbit laminectomy model. Biomed J 37: 218-224.

de Tribolet N, Porchet F, Lutz TW, Gratzl O, Brotchi J, van Alphen HA, van Acker RE, Benini A, Strommer KN, Bernays RL, Goffin J, Beuls EA, Ross JS (1998) Clinical assessment of a novel antiadhesion barrier gel: prospective, randomized, multicenter, clinical trial of ADCON-L to inhibit postoperative peridural fibrosis and related symptoms after lumbar discectomy. Am J Orthop 27: 111-120.

Doğulu F, Durdağ E, Cemil B, Kurt G, Özgün G (2009) The role of FloSeal in reducing epidural fibrosis in a rat laminectomy model. Neurol Neurochir Pol 43: 346-351.

Einhaus SL, Robertson JT, Dohan FC Jr, Wujek JR, Ahmad S (1997) Reduction of peridural fibrosis after lumbar laminotomy and discectomy in dogs by a resorbable gel (ADCON-L). Spine (Phila Pa 1976) 22: 1440-1447.

Farrokhi MR, Vasei M, Fareghbal S, Farrokhi N (2011) The effect of methylene blue on peridural fibrosis formation after laminectomy in rats: an experimental novel study. Spine J 11: 147-152.

Hahn SK, Park JK, Tomimatsu T, Shimoboji T (2007) Synthesis and degradation test of hyaluronic acid hydrogels. Int J Biol Macromol 10: 374-380.

He Y, Revel M, Loty B (1995) A quantitative model of post-laminectomy scar formation: effects of a nonsteroidal anti-inflammatory drug. Spine (Phila Pa 1976) 20: 557-563.

Hinton JL Jr, Warejcka DJ, Mei Y, McLendon RE, Laurencin C, Lucas PA, Robinson JS Jr (1995) Inhibition of epidural scar formation after lumbar laminectomy in the rat. Spine (Phila Pa 1976) 20: 564580.

Holtz G (1980) Prevention of postoperative adhesions. J Reprod Med 24: 141-146

Huberlant S, Fernandez H, Vieille P, Khrouf M, Ulrich D, deTayrac R, Letouzey V (2015) Application of a hyaluronic acid gel after intrauterine surgery may improve spontaneous fertility: a randomized controlled trial in New Zealand White rabbits. PLoS One 10: e0125610.

International Standardization Organization (1992) Biological evaluation of medical devices. Part 5. Test for cytotoxicity: in vitro methods. ISO 10993-5.
Jacobs RR, McClain O, Neff J (1980) Control of postlaminectomy scar formation: an experimental and clinical study. Spine (Phila Pa 1976) 5: 223-229.

Kato T, Haro H, Komori H, Shinomiya K (2005) Evaluation of hyaluronic acid sheet for the prevention of postlaminectomy adhesions. Spine J 5: 479-488.

Kaux JF, Samson A, Crielaard JM (2016) Hyaluronic acid and tendon lesions. Review. Muscles Ligaments Tendons J 5: 264-269.

LaRocca H, MacNab I. (1974) The laminectomy membrane: studies in its evaluation, characteristics, effects and prophylaxis in dogs. J Bone Joint Surg Br 56: 545-550.

Lawson KJ, Malycky JL, Berry JL, Steffee AD (1991) Lamina repair and replacement to control laminectomy membrane formation in dogs. Spine (Phila Pa 1976) 16 Suppl 6: S222-S226.

Lee JY, Stenzel W, Ebel H, Wedekind C, Ernestus RI, Klug N (2004) Mitomycin C in preventing spinal epidural fibrosis in a laminectomy model in rats. J Neurosurg 100 Spine Suppl 1: 52-55.

Lee JY, Stenzel W, Löhr M, Stützer H, Ernestus RI, Klug N (2006) The role of mitomycin C in reducing recurrence of epidural fibrosis after repeated operation in a laminectomy model in rats. J Neurosurg Spine 4: 329-333.

Lin CY, Peng HH, Chen MH, Sun JS, Liu TY, Chen $\mathrm{MH}$ (2015) In situ forming hydrogel composed of hyaluronate and polygalacturonic acid for prevention of peridural fibrosis. J Mater Sci Mater Med. 26: 168.

Lin C, Li XG, Cao LP, Li XL, Meng JR, Dong J, Yu L, Ding JD (2016) An injectable hydrogel with or without drugs for prevention of epidural scar adhesion after laminectomy in rats. Chin J Polym Sci 2: 147-163.

Liu Y, Skardal A, Shu XZ, Prestwich GD (2008) Prevention of peritendinous adhesions using a hyaluronan-derived hydrogel film following partialthickness flexor tendon injury. J Orthop Res 26: 562569.

Massie JB, Schimizzi AL, Huang B, Kim CW, Garfin SR, Akeson WH (2005) Topical high molecular weight hyaluronan reduces radicular pain post laminectomy in a rat model. Spine J 5: 494-502.

Mehdi Z, Seyed MM, Farid AA, Farid M, Marjan Z, Elham A, Zohreh H (2014) Reduction of epidural fibrosis and dural adhesions after lamina reconstruction by absorbable cement: an experimental study. Spine J 14: 113-118.

Nussbaum CE, McDonald JV, Baggs RB (1990) Use of Vicryl (polyglactin 910) mesh to limit epidural scar formation after laminectomy. Neurosurgery 26: 649-654.

Rajiv S, Drilling A, Bassiouni A, Harding M, James C, Robinson S, Moratti S, Wormald PJ (2017) Chitosan Dextran gel as an anti adhesion agent in a postlaminectomy spinal sheep model. J Clin Neurosci 40:153-156.

Robertson JT (1996) Role of peridural fibrosis in the failed back: a review. Eur Spine J 5 Suppl 1: S2-6.

Rodgers KE, Robertson JT, Espinoza T, Oppelt W, Cortese S, diZerega GS, Berg RA (2003) Reduction 
of epidural fibrosis in lumbar surgery with Oxiplex adhesion barriers of carboxymethylcellulose and polyethylene oxide. Spine J 3: 277-284.

Ross JS, Robertson JT, Frederickson RC, Petrie JL, Obuchowski N, Modic MT, de Tribolet N (1996) Association between peridural scar and recurrent radicular pain after lumbar discectomy: magnetic resonance evaluation. ADCON-L European Study Group. Neurosurgery 38: 855-861.

Sakai S, Ueda K, Taya M. (2015) Peritoneal adhesion prevention by a biodegradable hyaluronic acid-based hydrogel formed in situ through a cascade enzyme reaction initiated by contact with body fluid on tissue surfaces. Acta Biomater 24: 152-158.

Sae-Jung S, Jirarattanaphochai K, Sumananont C, Wittayapairoj K, Sukhonthamarn K (2015) Interrater reliability of the postoperative epidural fibrosis classification: a histopathologic study in the rat model. Asian Spine J 9: 587-594.

Semra I, M. Özgür T, Fatma OA, Seref D (2015) Effects of cross-linked high-molecular-weight hyaluronic acid on epidural fibrosis: experimental study. J Neurosurg Spine 22: 94-100.

Shih HN, Fang JF, Chen JH, Yang CL, Chen YH, Sung TH, Shih LY (2004) Reduction in experimental peridural adhesion with the use of a crosslink hyaluronate/collagen membrane. J Biomed Mater Res B Appl Biomater 71: 421-428.

Shin SJ, Lee JH, So J, Min K (2016) Anti-adhesive effect of poloxamer-based thermo-sensitive sol-gel in rabbit laminectomy model. J Mater Sci Mater Med. 27: 162.

Songer MN, Ghosh L, Spencer DL (1990) Effects of sodium hyaluronate on peridural fibrosis after lumbar laminotomy and discectomy. Spine (Phila Pa 1976) 15: 550-554.

Songer MN, Rauschning W, Carson EW, Pandit SM (1995) Analysis of peridural scar formation and its prevention after lumbar laminotomy and discectomy in dogs. Spine (Phila Pa 1976) 20: 571-580.

Su WY, Chen YC, Lin FH (2010) Injectable oxidized hyaluronic acid/adipic acid dihydrazide hydrogel for nucleus pulposus regeneration. Acta Biomater 6: 3044-3055.

Tao H, Fan H (2009) Implantation of amniotic membrane to reduce postlaminectomy epidural adhesions. Eur Spine J 8:1202-1212.

Varma DM, Gold GT, Taub PJ, Nicoll SB. (2014) Injectable carboxymethylcellulose hydrogels for soft tissue filler applications. Acta Biomater 10: 4996-5004.

Wang Y, Liang M, Zheng Z, Shi L, Su B, Liu J, Kaplan DL, Zhang B, Wang X (2015) Adhesion prevention after laminectomy using silk-polyethylene glycol hydrogels. Adv Healthc Mater. DOI: 10.1002/ adhm.201500392.

Yaacobi Y, Hamed LM, Kaul KS, Fanous MM (1992) Reduction of postoperative adhesions secondary to strabismus surgery in rabbits. Ophthalmic Surg 23: 123-128.

Yeo Y, Ito T, Bellas E, Highley CB, Marini R, Kohane DS. (2007) In situ cross-linkable hyaluronan hydrogels containing polymeric nanoparticles for preventing postsurgical adhesions. Ann Surg 245: 819-824.

Yong-Hing K, Reilly J, de Korompay V, KirkaldyWillis WH (1980) Prevention of nerve root adhesions after laminectomy. Spine (Phila Pa 1976) 5: 59-64.

Zhang L, Cao Z, Bai T, Carr L, Ella-Menye JR, Irvin C, Ratner BD, Jiang S (2013) Zwitterionic hydrogels implanted in mice resist the foreign-body reaction. Nat Biotechnol 31: 553-556.

\section{Discussion with Reviewers}

Marianna Peroglio: What could be the challenges in translating the use of the hydrogel from rat to human laminectomy for the prevention of epidural fibrosis? Authors: Our concern would be how to determine the safety and assess the efficacy of this hydrogel as an anti-adhesion agent after discectomy or laminectomy. Close monitoring and collection of safety data is very important before the routine use of a new device and it should not be undervalued. Such further studies should meet the essential requirements of the Medical Devices Directive. Unlike the animal study, direct evidences of dura or root adhesion can only be collected from gross evaluation in limited patients who receive reoperation. Indirect evidences from patient-reported outcome assessment are sometimes debatable, whereas postoperative back or leg pain should be multifactorial. An objective clinical tool, such as myelography, may be helpful.

Marianna Peroglio: For which other applications could this hydrogel potentially be used for, besides the prevention of epidural fibrosis?

Authors: Besides the prevention of epidural fibrosis, there are some potential clinical applications for which this hydrogel could be used. First, it is a potential vitreous substitute after vitrectomy ( $\mathrm{Su}$ et al., 2011; additional reference). Second, it plays a probable role in preventing other post-operative adhesions, such as intra-abdomen adhesions after open or endoscopic abdomen surgery, intrauterine adhesions after operative hysteroscopy and tendon adhesions. Third, this injectable hydrogel is a good candidate for cell or drug carrier. For example, this hydrogel could be a suitable cell carrier for nucleus pulposus (NP) cells in the treatment of NP degeneration. In addition, it should be a promising drug compound (e.g. epidural morphine-hydrogel compound for postoperative pain, anti-inflammatory drug-eluting hydrogel for facilitating epidural fibrosis prevention), whose cytocompatibility in the spine environment was proved in the current study.

Zhen Li: Are there already similar products available on the market? What are the main advantages of the current hydrogel compared with those?

Authors: The only FDA-approved adhesion barrier gel for spine surgery is carboxymethycellulose 
(CMC)/polyethylene oxide (PEO) gel (Oxiplex ${ }^{\circledR} / \mathrm{SP}$ Adhesion Barrier Gel, manufactured by FzioMed, San Luis Obispo, CA, USA and distributed under the trade names of Oxiplex ${ }^{\circledR} / S P$ Adhesion Barrier Gel, DePuy International, Leeds, UK and Medishield ${ }^{\mathrm{TM}}$ Adhesion Barrier Gel, Medtronic International Trading SARL, Tolochenaz, Switzerland). It is a flowing, viscoelastic gel with a degradation time of about 4 weeks, which is stored at room temperature and supplied sterile in a $3 \mathrm{~mL}$ syringe with a flexible applicator.

The possible advantages of our thermosensitive oxi-HA/ADH hydrogel is its longer degradation time and its sol-gel transformation property, which lessens the risk of ectopic leakage, especially in early upright activity after surgeries.

\section{Additional Reference}

Su WY, Chen KH, Chen YC, Lee YH, Tseng CL, Lin FH (2011) An injectable oxidated hyaluronic acid/adipic acid dihydrazide hydrogel as a vitreous substitute. J Biomater Sci Polym Ed 22: 1777-1797.

Editor note: The scientific editor for this paper was Brian Johnstone. 